\title{
Sex differences in DRL and active avoidance behaviors in the rat depend upon the day-night cycle
}

\author{
WILLIAM W. BEATTY \\ North Dakota State University, Fargo, North Dakota 58102
}

\begin{abstract}
Adult female rats acquired efficient DRL responding and shuttlebox avoidance behavior more quickly than did adult male rats only if the tests were conducted during the daytime portion of the day-night cycle. During the night there was no sex difference in either behavior.
\end{abstract}

Previous studies have demonstrated that female rats acquire shuttlebox avoidance responses (e.g., Beatty \& Beatty, 1970; Scouten, Grotelueschen, \& Beatty, 1975) and efficient DRL behavior (Beatty, 1973; Beatty, Studelska, \& Gerth, 1975; Kearly, van Hartesveldt, \& Woodruff, 1974) more rapidly than do males. In these experiments behavioral tests were always conducted during the daylight portion of the day-night cycle. Since there are marked sex differences in activity (e.g., Archer, 1975; Hitchcock, 1925) and the rat, like many other rodents, is most active at night (e.g., Richter, 1922; for reviews see Rusak \& Zucker, 1975; Zucker, Rusak, \& King, 1976), it seemed of interest to determine whether or not the sex differences in DRL and avoidance behavior observed in daytime tests would also appear at night. Based on diurnal activity rhythms, it might be expected that sex differences in DRL behavior would be reduced at night, while differences in active avoidance would be accentuated. Ostensibly consistent with this prediction is the recent demonstration that retention of passive avoidance behavior is better during the day than at night in male rats (Davies, Navaratnam, \& Redfern, 1973).

\section{METHOD}

\section{Subjects}

The animals were 32 male and 32 female albino rats of the Holtzman strain, about 120 days of age at the start of training. All had been tested for 1-2 days in an open field prior to the present experiment. The rats were caged singly in a temperaturecontrolled animal room with free access to food and water in the home cage except during DRL tests. During the DRL tests a food-deprivation schedule designed to maintain body weight at $85 \%$ of the original free-feeding level was imposed. No attempt to adjust for growth was made, since this factor is not important to sex differences in DRL in animals of this age (Beatty et al., 1975). Lights in the animal room were on from 0800 to 2000 .

Supported by NIH Grant HD 08206. Jerry Holzer, Steve Ness, Jeff Gerth, and Bruce O'Gara assisted in the testing of the animals.

\section{Apparatus}

DRL tests were conducted in four identical Gerbrands operant chambers equipped with a standard lever and a $45-\mathrm{mg}$ pellet feeder. A houselight (1820 bulb) was on during testing. The chambers were housed in sound-attenuating enclosures equipped with ventilation fans. An ADS $1800 \mathrm{E}$ laboratory computer programmed conditions and recorded performance.

Avoidance training was conducted in two identical shuttleboxes made of Lucite and aluminum $(41.5 \times 20.5 \times 11.5 \mathrm{~cm}$ high, i.d.). The grid floor was made of bronze welding rods spaced $1.4 \mathrm{~cm}$ apart. Two $6-\mathrm{W}$ ac lamps mounted on the side wall of each compartment of the shuttlebox provided the CS. Photocells detected the position of the animal. Scrambled ac shock from a Grason-Stadler E700 source was directed to either compartment of the shuttlebox by a relay system. Conventional electromechanical circuitry controlled conditions and recorded performance. Printout counters provided a trial-bytrial record of avoidance and escape responding. The apparatus contained no hurdle or barrier between compartments.

\section{Procedure}

DRL. When the rats attained deprivation body weight, they were trained to barpress for $45-\mathrm{mg}$ Noyes pellets on a CRF schedule. Following one or two sessions on CRF to stabilize responding, they were immediately shifted to a DRL 20 -sec reinforcement schedule. The day and night phases of the experiment were conducted in separate replicates. Animals in the night phase (16 of each sex) were given 30 -min test sessions in squads of four animals, two of each sex. The first squad was tested starting at $2100,1 \mathrm{~h}$ after the lights were turned off in the animal room. Animals in the day phase of the experiment were tested in a similar fashion, but the first squad of four rats did not begin its 30-min session until 1200 because of heavy demands on the computer control system during the morning hours. Since in an earlier study (Beatty, 1973) performance of animals trained in the morning was similar to that of the rats tested in the afternoon, in the current study, this was not regarded as an important problem. In both phases training continued for 40 daily sessions.

Avoidance. After completion of the DRL tests, the rats were returned to free feeding and 1-2 weeks later received avoidance training. The rats were placed in the shuttleboxes with the side wall lights on in both sides of the chamber. Spontaneous shuttling activity was recorded for $5 \mathrm{~min}$. Then avoidance training began and continued until the animal met a criterion of 10 consecutive avoidance responses or had received 200 trials. A trial began with the cessation of illumination in the side of the chamber occupied by the rat. If the rat shuttled before the end of the 10-sec CS-US interval, the CS terminated and shock did not occur. If the animal failed to avoid, the 1-mA shock US was 
Table 1

Mean Efficiency $\times 100$

\begin{tabular}{lcrrrrrrr}
\hline $\begin{array}{c}\text { Blocks of Five } \\
\text { Sessions }\end{array}$ & 1 & 2 & 3 & 4 & 5 & 6 & 7 & 8 \\
\hline Males-Day & 5.6 & 8.3 & 17.6 & 28.9 & 31.6 & 37.9 & 40.0 & 41.1 \\
Females-Day & 8.4 & 14.9 & 26.2 & 36.8 & 45.9 & 52.5 & 59.8 & 61.2 \\
Males-Night & 6.7 & 8.6 & 16.2 & 24.6 & 27.8 & 38.4 & 47.2 & 53.7 \\
Females-Night & 6.2 & 9.7 & 12.8 & 17.4 & 23.0 & 28.1 & 32.7 & 38.8 \\
\hline
\end{tabular}

turned on while the CS continued. Both were terminated by an escape response or after $10 \mathrm{sec}$. Termination of the trial initiated a 60-sec ITI. Half of the rats of each sex from each DRL replicate began avoidance training at 0900; for the remaining animals testing started at 2100 .

\section{RESULTS}

Table 1 presents the results of the DRL tests in terms of efficiency scores (reinforcements/responses). In tests conducted during the day, females performed more efficiently than males, particularly during the latter stages of training. By contrast, during the night tests this pattern was not observed and, in fact, males performed somewhat more efficiently than females. Analysis of these data revealed significant Sex by Time of Day $[F(1,60)=4.34, p<.05]$ and Sex by Time of Day by Testing Blocks $[\mathrm{F}(7 ; 420)=3.01, \mathrm{p}<.01]$ interactions. Subsequent analysis demonstrated that females tested during the day performed more efficiently than females tested at night and that females outperformed males during daytime tests during the last two testing blocks. Overall performance was somewhat less efficient at night $[F(1,60)=3.04, p<.10]$ but there was no significant difference between male and female performance on any testing block.

Examination of the response and reinforcement measures indicated that the groups that performed most efficiently tended to make fewer responses and earn more reinforcements than the less efficient groups, but statistical analyses did not reveal significant effects of sex or time of day on either measure.

Table 2 presents the results of the shuttlebox avoidance tests. Female rats met the learning criterion in fewer trials and made fewer escapes than did males, but only if testing occurred during the day. Reliable differences (both measures $p<.05$ ) were observed between males and females that were tested during the day, but at night there was no sex difference in performance. Examination of the data reveals little difference in

Table 2

Mean Performance to Criterion During Avoidance Tests

\begin{tabular}{lrr}
\hline & Escapes & Trials \\
\hline Males-Day & 108.4 & 144.5 \\
Females-Day & 65.6 & 89.9 \\
Males-Night & 110.6 & 134.9 \\
Females-Night & 104.3 & $: 31.4$ \\
\hline
\end{tabular}

performance of males as a function of the time of testing, but females acquired avoidance behavior more slowly at night than in the day. There were no reliable differences due to sex or time of testing on measures of spontaneous activity, escape latency, or the frequency of intertrial shuttling responses.

\section{DISCUSSION}

The present results revealed an unexpected interaction of sex differences in instrumental behavior with the day-night cycle. When tested during the day, females developed efficient responding on both the DRL and active avoidance tasks more rapidly than did males, as we have observed in earlier studies (e.g., Beatty, 1973; Beatty \& Beatty, 1970). At night sex differences were not apparent on either task. In both situations females performed more poorly in night tests; by contrast, males were little affected by the time of day tests occurred.

Two hypotheses might be advanced to explain the DRL data. First, since activity is much greater at night than during the day, especially in females, diurnal variations in activity might underlie the differences in DRL performance, at least in females. The hypothesis has obvious difficulties explaining why males tested at night performed somewhat more efficiently and made somewhat fewer responses than males trained during the day. A second explanation is based on the fact that, while rats of both sexes feed mainly at night, females consume a greater proportion of their total daily intake at night than do males (Balagura \& Devenport, 1970). Hence, females might be "hungrier" at night than in the day. This hypothesis encounters all of the same difficulties that beset the activity interpretation. In addition, the relevance of data on diurnal feeding patterns, under conditions of unrestricted access to food and water, to the deprivation conditions of the present experiment is surely questionable; in any event, performance of established DRL behavior is rather insensitive to variations in deprivation conditions (Conrad, Sidman, \& Herrnstein, 1958; Holz \& Azrin, 1963).

Neither of the above explanations can encompass the avoidance results. Diurnal variations in activity patterns predict better performance at night in both sexes, especially females. In fact, females acquired avoidance behavior more slowly at night than in the day. A recent finding from our laboratory (Beatty \& Holzer, Note 1) may explain this surprising effect. In that experiment we found that the magnitude of the sex difference in shock thresholds measured by the flinch-jump technique varied with the day-night cycle. Of particular importance was the finding that females were more responsive to shock (i.e., had lower jump thresholds) at night than in the day. Males exhibited no variation in responsiveness to shock as a function of the daynight cycle. From these results it is reasonable to suppose that at night superthreshold shocks are more painful for females than in the day. Since in daytime tests acquisition of avoidance behavior by females deteriorates at US intensities above $1.0 \mathrm{~mA}$ (Beatty \& Beatty, 1970), females may have acquired shuttlebox avoidance behavior more poorly at night because the US intensity was sufficiently painful to retard performance. 


\section{REFERENCE NOTE}

1. Beatty, W. W., \& Holzer, G. A. Sex differences in shock thresholds in rats and gerbils and the day-night cycle. Submitted for publication.

\section{REFERENCES}

ArCher, J. Rodent sex differences in emotional and related behavior. Behavioral Biology, 1975, 14, 451-479.

Balagura, S., \& Devenport, L. D. Feeding patterns of normal and ventromedial hypothalamic lesioned male and female rats. Journal of Comparative and Physiological Psychology, 1970, 71, 357-364.

BEATTY, W. W. Effects of gonadectomy on sex differences in DRL behavior. Physiology and Behavior, 1973, 10, $177-178$

Beatty, W. W., \& Beatty, P. A. Hormonal determinants of sex differences in active avoidance behavior and reactivity to electric shock in the rat. Journal of Comparative and Physiological Psychology, 1970, 73, 446-455.

Beatty, W. W., Studelska, D. R., \& Gerth, J. M. Some aspects of the development of sex differences in DRL behavior. Bulletin of the Psychonomic Society, 1975, 6, 622-624.

Conrad, D. G., Sidman, M., \& Herrnstein, R. J. The effect of deprivation upon temporally spaced responding. Journal of the Experimental Analysis of Behavior, 1958, 1, $59-65$.
Davies, J. A., Navaratnam, V., \& Redfern, P. H. A 24-hr rhythm in passive avoidance behavior in rats. Psychopharmacologia, 1973, 32, 211-214.

Hrтснсоск, F. A. Studies in vigor: V. The comparative activity of male and female albino rats. American Journal of Physiology, 1925, 75, 205-210.

Holz, W. C., \& AzRiN, N. H. A comparison of several procedures for eliminating behavior. Journal of the Experimental Analysis of Behavior, 1963, 3, 399-406.

Kearly, R. C., VAN HaRTeSVELdT, C., \& WoOdRUfF, M. L. Behavioral and hormonal effects of hippocampal lesions in male and female rats. Physiological Psychology, 1974, 2, 187-196.

Richter, C. P. A behavioristic study of the activity of the rat. Comparative psychology monographs, 1922, 1(Whole No. 2). Reprinted in E. M. Blass (Ed.), The psychobiology of Curt Richter. Baltimore: York Press, 1976.

Rusak, B., \& ZuCKER, I. Biological rhythms and animal behavior. Annual Review of Psychology, 1975, 26, 137-171.

Scouten, C. W., Grotelueschen, L., \& Beatty, W. W. Androgens and the organization of sex differences in active avoidance behavior in the rat. Journal of Comparative and Physiological Psychology, 1975, 88, 264-270.

ZuCKER, I., RusAK, B., \& KING, R. G. Neural bases for circadian rhythms in rodent behavior. In A. H. Riesen \& R. F. Thompson (Eds.), Advances in psychobiology (Vol. 3). New York: Wiley, 1976.

(Received for publication March 21, 1977.) 